\title{
BMI and risk of gestational diabetes among women of South Asian and Chinese ethnicity: a population-based study
}

\author{
Stephanie H. Read ${ }^{1,2} \cdot$ Laura C. Rosella $^{2,3,4} \cdot$ Howard Berger $^{5} \cdot$ Denice S. Feig ${ }^{2,6,7,8} \cdot$ Karen Fleming $^{9} \cdot$ Joel G. Ray ${ }^{2,6,7,10}$. \\ Baiju R. Shah ${ }^{2,6,7,11} \cdot$ Lorraine L. Lipscombe ${ }^{1,2,6,7}$
}

Received: 28 July 2020 / Accepted: 22 October 2020 / Published online: 24 January 2021

(C) The Author(s), under exclusive licence to Springer-Verlag GmbH, DE part of Springer Nature 2021

\begin{abstract}
Aims/hypothesis The aim of this study was to examine how BMI influences the association between Asian ethnicity and risk of gestational diabetes (GDM).

Methods This population-based cohort study included pregnant women without pre-existing diabetes mellitus in Ontario, Canada between 2012 and 2014. Women of Chinese and South Asian ethnicity were identified using a validated surname algorithm. GDM was ascertained using hospitalisation codes. The relationship between ethnicity and GDM was modelled using modified Poisson regression, adjusted for maternal age, pre-pregnancy BMI, parity, previous GDM, long-term residency status, income quintile and smoking status. An interaction term between ethnicity and pre-pregnancy BMI was tested.

Results Of 231,618 pregnant women, 9289 (4.0\%) were of South Asian ethnicity and 12,240 (5.3\%) were of Chinese ethnicity. Relative to women from the general population, in whom prevalence of GDM was 4.3\%, the adjusted RR of GDM was higher among those of South Asian ethnicity (1.81 [95\% CI 1.64, 1.99]) and Chinese ethnicity (1.66 [95\% CI 1.53, 1.80]). The association between GDM and Asian ethnicity remained significant across BMI categories but differed according to BMI. The prevalence of GDM exceeded $5 \%$ at an estimated BMI of $21.5 \mathrm{~kg} / \mathrm{m}^{2}$ among South Asian women, $23.0 \mathrm{~kg} / \mathrm{m}^{2}$ among Chinese women and $29.5 \mathrm{~kg} / \mathrm{m}^{2}$ among the general population.

Conclusions/interpretation The risk of GDM is significantly higher in South Asian and Chinese women, whose BMI is lower than that of women in the general population. Accordingly, targeted GDM prevention strategies may need to consider lower BMI cut-points for Asian populations.
\end{abstract}

Keywords Diabetes $\cdot$ Immigrants $\cdot$ Pregnancy $\cdot$ Race $\cdot$ Racial disparities

\section{Abbreviations}

BORN Better Outcomes Registry and Network

GDM Gestational diabetes

PAF Population attributable fraction

Lorraine L. Lipscombe

Lorraine.lipscombe@wchospital.ca

1 Women's College Research Institute, Women's College Hospital, Toronto, ON, Canada

2 ICES, Toronto, ON, Canada

3 Dalla Lana School of Public Health, University of Toronto, Toronto, ON, Canada

4 Public Health Ontario, Toronto, ON, Canada

5 Division of Maternal-Fetal Medicine, St Michael's Hospital, Toronto, ON, Canada

\section{Introduction}

Gestational diabetes (GDM) is a metabolic disorder of pregnancy that currently affects around $5-9 \%$ of pregnancies [1].

6 Department of Medicine, University of Toronto, Toronto, ON, Canada

7 Institute of Health Policy, Management and Evaluation, University of Toronto, Toronto, ON, Canada

8 Sinai Health System, Toronto, ON, Canada

9 Department of Family and Community Medicine, Sunnybrook Health Sciences Centre, Toronto, ON, Canada

10 Department of Obstetrics and Gynaecology, St Michael's Hospital, Toronto, ON, Canada

11 Department of Medicine, Sunnybrook Health Sciences Centre, Toronto, ON, Canada 


\section{Research in context}

\section{What is already known about this subject?}

- South Asian populations are at high risk of gestational diabetes (GDM)

- Increasing BMI is associated with higher risk of GDM

- Evidence on the effect of ethnicity on the association between BMI and GDM is lacking

What is the key question?

- Does ethnicity modify the association between BMI and GDM?

What are the new findings?

- GDM was found to affect $5 \%$ of pregnancies and risk was considerably higher in South Asian and Chinese women

- Chinese and South Asian women develop GDM at a considerably lower BMI than women in the general population

How might this impact on clinical practice in the foreseeable future?

- Interventions aimed at reducing excessive weight and obesity may have less impact in reducing GDM prevalence in South Asian and Chinese women

Established adverse neonatal effects of GDM include macrosomia, preeclampsia, preterm delivery and neonatal death [2]. While glucose tolerance normalises in most women after delivery, those who develop GDM during pregnancy have a tenfold increased risk of developing subsequent type 2 diabetes [3].

Risk of GDM is heterogeneous and is influenced by factors such as BMI and ethnicity $[4,5]$. Relative to normal-weight women, risk of GDM is fourfold higher in obese women as defined by a BMI $>30 \mathrm{~kg} / \mathrm{m}^{2}$ [5]. GDM is also more prevalent in most ethnic minority populations [6-9]. In particular, evidence indicates that South Asian and Chinese women have a higher risk of GDM when compared with white women [7]. Despite this, the prevalence of obesity is lower in South Asian and Chinese women than it is in white women [10]. Explanations for these conflicting patterns of GDM risk include differences in visceral fat distribution and other genetic or epigenetic factors. Evidence suggests that Asian populations have a higher percentage body fat for a given BMI than white populations $[11,12]$ and that the risk of adverse health outcomes such as type 2 diabetes and CVD increases at lower BMI values [13]. As a result, the WHO recommends a lower cut-off for defining 'overweight' in Asian populations ( $>23 \mathrm{~kg} / \mathrm{m}^{2}$ ) compared with the general population $\left(>25 \mathrm{~kg} / \mathrm{m}^{2}\right)$. Few studies have investigated how risk of GDM is influenced by differences in maternal BMI when comparing Asian women with women in the general population. Furthermore, while there is some evidence that immigrant women have greater risk of GDM than non-immigrant women, less is known about how immigrant status influences the association between Asian ethnicity and GDM [7].
Understanding differences in the association between ethnicity and GDM by BMI is important for identifying optimal BMI targets for women entering pregnancy, to reduce their risk of GDM and, subsequently, adverse neonatal events. Clinicians will also be better placed to risk-stratify women to guide GDM prevention strategies early in pregnancy.

Using population-based health administrative datasets within a single-payer health system, we aimed to examine the effect of BMI on the association between Asian ethnicity and GDM in a large population of pregnant women in Ontario, Canada. We additionally explored the influence of immigrant status on this relationship.

\section{Methods}

Data sources Data were obtained from population-based administrative datasets held at ICES, an independent, nonprofit research institute whose legal status under Ontario's health information privacy law allows it to collect and analyse healthcare and demographic data without consent for the purposes of health system evaluation and improvement. The following administrative databases were used: registered persons database for demographics including neighbourhood income quintile and vital status; Canadian Institute of Health Information discharge abstract database for hospital admission and discharge data; Ontario Health Insurance Plan; Ontario's free healthcare plan for comorbidity data; and Ontario Laboratories Information System (OLIS) for laboratory data. The Better Outcomes Registry and Network (BORN), Ontario's perinatal registry, was the primary source of data for identifying the cohort and key pregnancy-related 
variables. This dataset was established in 2009 and captures maternal and neonatal information from hospitals, midwifery practice groups, specialised antenatal clinics, prenatal screening laboratories and fertility clinics relating to all pregnancies occurring across Ontario. BORN is funded by the Ontario Ministry of Health and Long-Term Care and supported by the Children's Hospital of Eastern Ontario. The Immigration, Refugees and Citizenship Canada Permanent Resident Database was used to identify individuals who immigrated to Canada since 1985 [14]. Details regarding these databases can be found at: https:/www.ices.on.ca/Data-andPrivacy/ICES-data/Data-dictionary. The datasets are linked using unique encoded identifiers and are analysed at ICES. The use of data in this project was authorised under section 45 of Ontario's Personal Health Information Protection Act, which does not require review by a Research Ethics Board.

Study design and participants This retrospective cohort study included all women aged 16-50 years at date of delivery who delivered a baby in hospital in Ontario between 1 April 2012 and 31 March 2014. For women who had multiple pregnancies during this period, only the first pregnancy was included. The following women were excluded: those who were ineligible for healthcare; those who were not a resident of Ontario in the 2 years prior to the date of delivery; and those who had pre-existing diabetes. Pre-existing diabetes was defined as a record in the Ontario Diabetes Database $\geq 150$ days before the delivery date based on a validated algorithm to identify diabetes from administrative data sources [15].

Outcome and covariates The primary outcome was a diagnosis of GDM during the index pregnancy, defined as an ICD-10 code (http://apps.who.int/classifications/icd10/browse/2016/ en) for GDM (O24) or diabetes (E10, E11, E12, E13, E14) during the index hospitalisation. Screening for diabetes is offered to all pregnant women, between the 24th and 28th week of pregnancy in Canada. The diagnostic threshold for GDM changed during the study period, with lower glucose thresholds implemented in 2013 [16, 17]. Details of the change are detailed in the electronic supplementary material (ESM) Table 1. Maternal Asian ethnicity was defined using a validated algorithm, which utilises surnames to identify people of South Asian and Chinese ethnicity; all others ethnicities were categorised as the general population group [18]. The algorithm has $>99.5 \%$ specificity but lower sensitivity (50\% for South Asian and $80 \%$ for Chinese ethnicity). Since immigration status could be determined from 1985 onwards, women were classified as long-term residents if they did not have an immigration record from 1985 onwards. Women with an immigration record after 1985 were classified as non-longterm residents. Data on pre-pregnancy maternal BMI, smoking status and parity were obtained from the BORN database. In a recent data quality assessment, maternal height and pre-pregnancy weight records in BORN, from which BMI is calculated, exhibited excellent agreement with data from patients' charts [19]. Neighbourhood income was based upon census data, with average household incomes attributed to individuals within specified areas containing up to 700 individuals, and then divided into quintiles. Rurality was measured using the continuous RIO2008 score [20]. Individuals living in a community that had a RIO score of 40 or above were defined as having a rural residence. Previous GDM was ascertained using hospitalisation records.

Statistical analyses Baseline characteristics of the study population were described by ethnicity. Missing data were imputed using multiple imputation [21] and complete case analyses were conducted as sensitivity analyses. Age-standardised risk of GDM was calculated for each ethnicity group, BMI category and long-term residency category by direct standardisation using the study population distribution. Unadjusted rates were also calculated and presented in the ESM. Modified Poisson regression models were used to estimate RR (95\% CI) of GDM [22]. All models included BMI and were sequentially adjusted for age at delivery, parity $(0,1$, 2, 3, >3), long-term residency (long-term resident/non-longterm resident), income quintile (1 [lowest income] to 5 [highest income]), previous GDM (yes/no/not applicable) and smoking status (yes/no). An interaction term between ethnicity and BMI was included in all models. BMI was first included in modified Poisson regression models as a categorical variable according to the WHO's definition (normal $<25 \mathrm{~kg} / \mathrm{m}^{2}$; overweight $25 \mathrm{~kg} / \mathrm{m}^{2}$ to $<30 \mathrm{~kg} / \mathrm{m}^{2}$; obese $\geq 30 \mathrm{~kg} / \mathrm{m}^{2}$ ). BMI was subsequently modelled as a linear term, after checking for non-linearity using restricted cubic splines with knot placement based upon the percentile distribution of BMI. Models were also stratified by long-term residency. Risk differences were calculated by using the identity link function. All statistical analyses were conducted in R (version 3.5.1) [23]. Predicted probability estimates derived from Poisson regression models have been plotted using ggplot (version 3.1.0) [24]. For illustration, the predicted probabilities are presented for nulliparous women aged 31 years, nonsmokers and in income quintile 3.

\section{Results}

The study population consisted of 231,618 women without pre-existing diabetes who delivered a baby in hospital between April 2012 and March 2014. ESM Table 2 presents a comparison of people with and without missing data. There were 9289 (4.0\%) South Asian women and 12,240 (5.3\%) Chinese women; the remaining 210,089 (90.7\%) were categorised as general population. Of the study population, 10,895 (4.7\%) women developed GDM during pregnancy: 
9.9\% of South Asian women; $8.2 \%$ of Chinese women; and $4.3 \%$ of general population women. Most of the study population were long-term residents $(74.6 \%)$. The mean \pm SD prepregnancy BMI was $25.5 \pm 6.6 \mathrm{~kg} / \mathrm{m}^{2} ; 76,578(33.1 \%)$ and $32,922(14.2 \%)$ of the study population were classified as overweight $\left(25-30 \mathrm{~kg} / \mathrm{m}^{2}\right)$ and obese $\left(>30 \mathrm{~kg} / \mathrm{m}^{2}\right)$, respectively.

Table 1 presents the characteristics of the study population by ethnicity. Compared with general population women,
South Asian and Chinese women were slightly older at delivery, had a lower pre-pregnancy weight, were less likely to be long-term residents, and were most likely to deliver babies that were small for gestational age (using the Canadian growth chart). The mean pre-pregnancy BMI of the South Asian, Chinese and general population women was $24.5 \mathrm{~kg} / \mathrm{m}^{2}$, $23.0 \mathrm{~kg} / \mathrm{m}^{2}$ and $25.6 \mathrm{~kg} / \mathrm{m}^{2}$, respectively.

Age-standardised prevalence rates for GDM by ethnicity, BMI and long-term residency status are presented in Table 2.
Table 1 Characteristics of the study participants

\begin{tabular}{|c|c|c|c|}
\hline Characteristic & $\begin{array}{l}\text { Chinese } \\
\text { ethnicity } \\
(N=12,240)\end{array}$ & $\begin{array}{l}\text { South Asian } \\
\text { ethnicity } \\
(N=9289)\end{array}$ & $\begin{array}{l}\text { General } \\
\text { population } \\
(N=210,089)\end{array}$ \\
\hline \multicolumn{4}{|l|}{ Demographics } \\
\hline Median (IQR) age at delivery, years & $33(6)$ & $32(6)$ & $31(8)$ \\
\hline \multicolumn{4}{|l|}{ Income quintile, $n(\%)$} \\
\hline 1 (lowest) & $1963(16.1)$ & $1847(19.9)$ & $43,287(20.7)$ \\
\hline 2 & $2718(22.3)$ & $2330(25.1)$ & $40,515(19.4)$ \\
\hline 3 & $2376(19.5)$ & $2417(26.1)$ & $42,606(20.3)$ \\
\hline 4 & $2989(24.5)$ & $1632(17.6)$ & $45,954(21.9)$ \\
\hline 5 (highest) & $2145(17.6)$ & $1048(11.3)$ & $37,011(17.7)$ \\
\hline Rurality, $n(\%)$ & $81(0.7)$ & $33(0.4)$ & $24,105(11.5)$ \\
\hline Long-term resident, $n(\%)$ & $4350(35.5)$ & $2923(31.5)$ & $165,585(78.8)$ \\
\hline \multicolumn{4}{|l|}{ Weight and smoking measures } \\
\hline Mean (SD) height, cm & $161.1(6.4)$ & $160.9(6.4)$ & $164.1(7.4)$ \\
\hline Mean (SD) weight gain, $\mathrm{kg}$ & $15.0(13.1)$ & $14.1(12.2)$ & $15.0(13.5)$ \\
\hline Mean (SD) pre-pregnancy BMI, $\mathrm{kg} / \mathrm{m}^{2}$ & $23.0(5.7)$ & $24.5(6.0)$ & $25.6(6.6)$ \\
\hline Mean (SD) pre-pregnancy weight, $\mathrm{kg}$ & $57.3(12.4)$ & $63.1(14.2)$ & $69.2(18.1)$ \\
\hline Smoker, $n(\%)$ & $114(0.9)$ & $71(0.7)$ & $9409(4.5)$ \\
\hline \multicolumn{4}{|l|}{ Parity, $n(\%)$} \\
\hline 0 & $5574(47.8)$ & $3694(41.1)$ & $90,361(43.6)$ \\
\hline 1 & $4683(40.2)$ & $3780(42.0)$ & $72,791(35.1)$ \\
\hline 2 & $1147(9.8)$ & $1196(13.3)$ & $29,173(14.1)$ \\
\hline 3 & 190 (1.6) & $234(2.6)$ & $9233(4.5)$ \\
\hline$>3$ & $57(0.5)$ & $87(1.0)$ & $5587(2.7)$ \\
\hline \multicolumn{4}{|l|}{ Prior pregnancy conditions, $n(\%)$} \\
\hline GDM & $278(2.3)$ & $267(2.9)$ & $3033(1.4)$ \\
\hline Gestational hypertension & $179(1.5)$ & $109(1.2)$ & $5127(2.4)$ \\
\hline Preeclampsia & $39(0.3)$ & $32(0.3)$ & $1186(0.6)$ \\
\hline \multicolumn{4}{|l|}{ Hypertension in the index pregnancy, $n(\%)$} \\
\hline Preeclampsia & $129(1.1)$ & $82(0.8)$ & $3236(1.5)$ \\
\hline Gestational hypertension & $336(2.7)$ & $206(2.2)$ & $8023(3.8)$ \\
\hline \multicolumn{4}{|l|}{ Newborn characteristics } \\
\hline Mean (SD) newborn weight, $g$ & $3168.5(558.8)$ & 3277 (509.4) & $3381.4(594.6)$ \\
\hline $\begin{array}{l}\text { Large-for-gestational-age birthweight, } n \\
\text { (\%) }\end{array}$ & 447 (4.9) & $678(5.6)$ & $22,076(10.6)$ \\
\hline $\begin{array}{l}\text { Small-for-gestational-age birthweight, } n \\
(\%)\end{array}$ & $1524(16.9)$ & $1246(10.5)$ & $17,838(8.7)$ \\
\hline Stillbirth, $n(\%)$ & $17(0.2)$ & $21(0.2)$ & $388(0.2)$ \\
\hline
\end{tabular}

Note: Not all column percentages will total $100 \%$ due to the presence of missing data 
Table 2 Age-standardised prevalence of GDM by long-term resident status, ethnicity and prepregnancy BMI

\begin{tabular}{llcc}
\hline Residency & $\begin{array}{l}\text { Chinese ethnicity } \\
(N=12,240)\end{array}$ & $\begin{array}{l}\text { South Asian ethnicity } \\
(N=9289)\end{array}$ & $\begin{array}{l}\text { General population } \\
(N=210,089)\end{array}$ \\
\hline Long-term residents & & & \\
Normal weight $\left(<25 \mathrm{~kg} / \mathrm{m}^{2}\right)$ & $5.2(4.5,6.4)$ & $5.7(4.7,7.2)$ & $2.2(2.1,2.3)$ \\
Overweight $\left(25-30 \mathrm{~kg} / \mathrm{m}^{2}\right)$ & $8.2(6.2,15.3)$ & $9.5(7.2,16.7)$ & $3.6(3.4,3.8)$ \\
Obese $\left(>30 \mathrm{~kg} / \mathrm{m}^{2}\right)$ & $6.7(4.3,14.1)$ & $12.1(8.8,17.5)$ & $7.2(6.9,7.5)$ \\
Overall & $5.8(5.2,6.9)$ & $7.5(6.5,8.8)$ & $3.6(3.5,3.7)$ \\
Non-long-term residents & & & $5.5(5.2,8.7)$ \\
Normal weight $\left(<25 \mathrm{~kg} / \mathrm{m}^{2}\right)$ & $6.9(6.3,9.2)$ & $8.9(7.8,10.4)$ & $8.1(7.6,8.7)$ \\
Overweight $\left(25-30 \mathrm{~kg} / \mathrm{m}^{2}\right)$ & $9.2(7.6,>100)$ & $13.4(11.7,20.2)$ & $10.0(9.3,11.0)$ \\
Obese $\left(>30 \mathrm{~kg} / \mathrm{m}^{2}\right)$ & $8.4(6.3,765.3)$ & $15.4(12.6,769.1)$ & $6.8(6.6,7.1)$ \\
Overall & $7.4(6.9,9.6)$ & $10.9(10.0,12.2)$ & \\
\hline
\end{tabular}

Prevalence is presented as $\%(95 \% \mathrm{CI})$
Crude prevalence rates for GDM by ethnicity, BMI and longterm residency status are presented in ESM Table 3. After standardisation, GDM prevalence was highest among South Asian women (9.6\% [95\% CI 9.0, 10.5]), followed by Chinese women (6.9\% [95\% CI 6.4, 7.6]) and then women in the general population ( $4.3 \%$ [95\% CI 4.2, 4.4]). Prevalence was higher in overweight and obese women than in normalweight women in all ethnic groups. Of the women who developed GDM, the mean BMI of the South Asian, Chinese and general population group was $25.9 \mathrm{~kg} / \mathrm{m}^{2}, 23.7 \mathrm{~kg} / \mathrm{m}^{2}$ and $28.3 \mathrm{~kg} / \mathrm{m}^{2}$, respectively. Non-long-term residents also had higher GDM prevalence than long-term residents (Table 2). These patterns were similar in the unadjusted analyses.

After adjusting for BMI and other covariates, the risk of GDM was significantly higher in Chinese (RR 1.66 [95\% CI $1.53,1.80]$ ) and South Asian (RR 1.81 [95\% CI 1.64, 1.99]) women compared with general population women (ESM

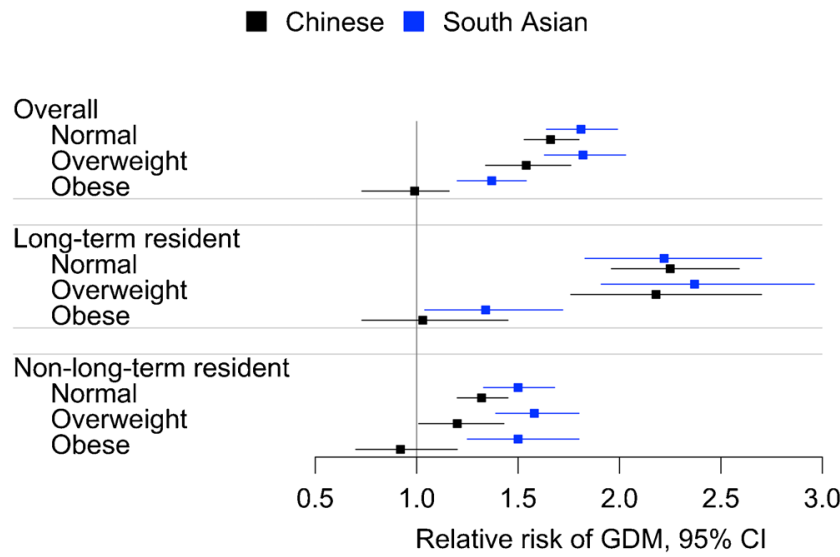

Fig. 1 RR (95\% CI) of developing GDM in relation to ethnicity, BMI and long-term resident status, with women from the general population serving as the referent. Estimates are adjusted for maternal age at delivery, parity, previous GDM, long-term residency, income quintile and smoking status. BMI was classified as normal $\left(<25 \mathrm{~kg} / \mathrm{m}^{2}\right)$, overweight $\left(25 \mathrm{~kg} / \mathrm{m}^{2}\right.$ to $\left.<30 \mathrm{~kg} / \mathrm{m}^{2}\right)$ or obese $\left(\geq 30 \mathrm{~kg} / \mathrm{m}^{2}\right)$
Table 4). The absolute risk difference was $2.01 \%$ (95\% CI $1.33,2.69)$ for Chinese and $2.28 \%$ (95\% CI 1.43, 3.13) for South Asian women (ESM Table 5).

Overweight (RR 1.54 [95\% CI 1.45, 1.61]) and obese (RR 2.50 [95\% CI $2.38,2.62]$ ) women had significantly increased risk of GDM compared with normal-weight women. Importantly, normal-weight and overweight South Asian and Chinese women remained at significantly increased risk of

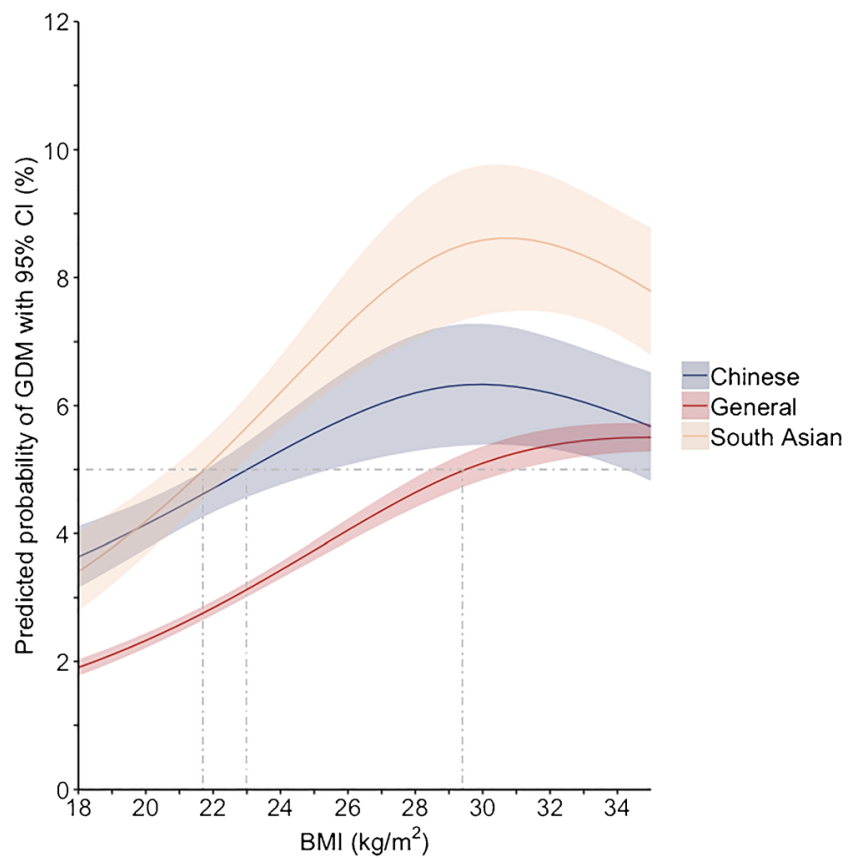

Fig. 2 Predicted probability of developing GDM by pre-pregnancy BMI among South Asian, Chinese and general population women. Estimates were derived using Poisson regression, adjusted for age, income quintile, smoking status, parity, ethnicity, BMI and an interaction term between ethnicity and BMI. The lines depict ethnicity and the shading shows $95 \%$ CIs. The dashed lines represent the levels of BMI for each ethnicity at which the predicted probability of GDM is 5\%. For illustration, the predicted probabilities are presented for nulliparous women aged 31 years, who are non-smokers and are in income quintile 3 
GDM compared with general population women in those categories. While this association remained significant for obese South Asian women, there was no difference in risk between obese women of Chinese ethnicity and obese general population women (Fig. 1). Non-long-term residents were also at greater risk of GDM after adjustment (RR 1.73 [95\% CI 1.66, 1.81]), and the association between ethnicity and GDM was stronger for long-term residents than non-longterm residents, with comparable trends across weight categories (Fig. 1). ESM Fig. 1 presents estimates stratified by longterm residential status from complete case analyses.

The relationship between increasing BMI and predicted GDM prevalence by ethnicity is shown in Fig. 2 . The prevalence of GDM exceeded 5\% at an estimated BMI of $21.5 \mathrm{~kg} /$ $\mathrm{m}^{2}$ and $23.0 \mathrm{~kg} / \mathrm{m}^{2}$ for South Asian and Chinese women, respectively, whereas $5 \%$ prevalence was not reached until a BMI of $29.5 \mathrm{~kg} / \mathrm{m}^{2}$ for women in the general population (Fig. 2). The association between GDM and increasing BMI differed between general population and ethnic groups, with a larger difference noted for South Asian women.

\section{Discussion}

Using province-level data from Ontario, Canada, we have conducted the largest study to date to examine the association between BMI and GDM by ethnicity. Approximately 5\% of pregnancies between 2012 and 2014 were affected by GDM, and South Asian and Chinese women had a significantly higher risk of GDM compared with general population women regardless of BMI status. Most notably, the GDM prevalence in South Asian and Chinese women with a BMI of $21.5 \mathrm{~kg} / \mathrm{m}^{2}$ and $23.0 \mathrm{~kg} / \mathrm{m}^{2}$, respectively, was equivalent to GDM prevalence in general population women with BMI $29.5 \mathrm{~kg} / \mathrm{m}^{2}$. These findings indicate that while BMI is an important risk factor for GDM in women of South Asian and Chinese ethnicity, this risk begins to increase at far lower BMI levels when compared with the general population.

Limited studies have examined the association between BMI and GDM in Asian populations. In agreement with the findings reported here, a London-based study among 53,264 mothers found that risk of GDM in South Asian and East Asian women with BMI values of $21 \mathrm{~kg} / \mathrm{m}^{2}$ was equivalent to the risk of GDM in white women with BMI values of $30 \mathrm{~kg} /$ $\mathrm{m}^{2}$ [25]. Another study conducted in a cohort of women in California found that GDM prevalence was considerably higher among Asian women than among non-Hispanic white women (10.2\% vs $4.5 \%)$ [26]. In the same clinical study, the authors found that being overweight or obese accounted for $52 \%$ of the GDM risk in non-Hispanic white women but only $23 \%$ of GDM risk in Asian women. Another California-based study reported higher GDM prevalence among Chinese (15.3\%) and Asian Indian (19.3\%) women than among non-
Hispanic white women (7.0\%) [27]. The population attributable fraction (PAF) of overweight/obese women was $28.9 \%$ for non-Hispanic white ethnicity, $25.5 \%$ for Asian Indian ethnicity and $7.9 \%$ for Chinese ethnicity. However, upon using the WHO/ADA BMI cut-off points, the PAFs of overweight and obese women increased to $39.0 \%$ and $22.9 \%$ for those of Asian Indian and Chinese ethnicity, respectively. Conversely, an Australian study of GDM prevalence in Australian and New Zealand women compared with South Asian women found no evidence of an interaction between BMI and ethnicity [28]. Our study provides support for the suggestion that the effect of BMI on GDM risk differs in South Asian compared with general population women.

There are numerous proposed biological, environmental, social and behavioural explanations for the increased risk of GDM at lower BMI levels among South Asian and Chinese women. One biological explanation relates to differences in the distribution of body fat across ethnicities. Evidence suggests that compared with white women, South Asian women have greater levels of visceral abdominal fat, an important determinant of insulin resistance. These observations may relate to the 'thrifty phenotype hypothesis', which suggests that some populations may be more susceptible to developing the metabolic syndrome due to exposure to undernutrition in early life [29]. Poor fetal and infant nutrition is thought to create a thrifty phenotype that is ill adapted to later periods of high-energy food consumption. For example, low birthweight has been shown to be an independent marker of subsequent GDM risk, highlighting the likely important role of early life factors in predisposing to future disease [30, 31]. These epigenetic changes can be transmitted to the second generation and therefore the excess risk of GDM may remain even among long-term resident Asian women, as was shown in our study [32]. Furthermore, compared with white women, South Asian women have been found to have lower BMI values for the same percentage body fat $[11,12]$. Prepregnancy BMI also has a greater influence on insulin resistance in pregnancy in Asian women than in white women [33]. Together, these observations suggest that BMI may not be a sufficient marker of metabolic risk in Asian populations and that markers of visceral fat and insulin resistance may be more important for predicting susceptibility to GDM and diabetes.

A further explanation for our finding of increased prevalence of GDM in Chinese women even at low BMIs may relate to the two-step GDM screening process used in Canada. Using this approach, women with positive glucose challenge test results undergo a GTT and GDM is diagnosed if one of fasting, $1 \mathrm{~h}$ and $2 \mathrm{~h}$ glucose values exceed a given threshold. Evidence from the Hyperglycaemia and Adverse Pregnancy Outcome (HAPO) study indicates that Asian women, particularly Chinese women, may be more likely to have elevated 1 and $2 \mathrm{~h}$ glucose values compared with white 
women. In contrast, women of white ethnicity were more likely to have elevated fasting GTT values. This disparity could there therefore lead to more GDM diagnoses in Asian women than in white women.

We found that GDM prevalence was lower in long-term residents than in non-long-term residents but that disparities in GDM risk between general population women and South Asian women were largest in long-term resident women. Several USA-based studies have also found that the risk of GDM was much higher in immigrant women than in USAborn women, regardless of ethnicity [7, 27, 34-36]. The mechanism for the relatively higher GDM risk among longterm residents compared with non-long-term residents of Asian ethnicity is unclear. It is likely that the combined influence of an increased genetic predisposition to fat accumulation, country of birth differences and exposure to an obesogenic environment upon entering Canada may have contributed to this finding.

BMI is a key modifiable risk factor that may be targeted to reduce GDM risk. Randomised control trials of lifestyle interventions to reduce GDM incidence have reported mixed findings, and have primarily been conducted among high risk women who previously had a GDM pregnancy or who had high BMI $\left(>29 \mathrm{~kg} / \mathrm{m}^{2}\right)$ [37]. Given the comparatively high risk of GDM in South Asian and Chinese women even at low BMIs, further studies are required to identify whether GDM risk can be reduced through lifestyle interventions in these populations. One lifestyle intervention study conducted among Chinese women with a mean BMI of $23.6 \mathrm{~kg} / \mathrm{m}^{2}$ found no difference in risk of GDM between intervention and control groups [38]. This finding may suggest that achieving GDM risk reduction in low-BMI populations may be difficult to achieve. However, neither did the intervention result in a significant difference in gestational weight gain between the groups, possibly reflecting an ineffective intervention. Given the high prevalence of GDM in South Asian and Chinese women, identifying interventions that reduce GDM risk in these ethnicities remains a key research priority.

Strengths and limitations A key strength of this study was the use of routinely collected datasets of a full population covered in a single-payer system. This increased the likely generalisability of the findings, limited selection biases and ensured a sufficiently large sample size to allow for stratified analyses. We also had access to population-level data on prepregnancy BMI (which is often missing from health administrative data) and a validated algorithm to identify individuals of South Asian and Chinese ethnicities, which are two of the largest ethnic minority groups in Canada [39].

A number of limitations should be mentioned. First, prepregnancy BMI data were missing for $20.7 \%$ of the women; we addressed this using multiple imputation. Sensitivity analyses using complete case analyses yielded similar results to those reported in multiply imputed data. A second limitation is that data relating to immigration status prior to 1985 were not available and therefore it was not possible to classify the immigration status of women over the age of 33 years, representing one-third of the cohort. We therefore opted to classify women based on whether they were long-term residents or not. A third limitation was the unavailability of a number of potential confounding factors including family history and lifestyle patterns, such as dietary patterns. Fourth, the diagnostic criteria for GDM changed during the study period; this change likely led to an increase in prevalence of GDM but it is unknown whether the associations between BMI, ethnicity and GDM were affected differentially. Finally, while the surname algorithm exhibits $99.7 \%$ specificity for both South Asian and Chinese ethnicities compared with self-reported ethnicity, its lower sensitivity means that a number of South Asian and Chinese women were likely included in the general population group [18]. Furthermore, the general population group also includes women from other higher risk ethnicities such as white African-Caribbean and Hispanic. Given that each of these ethnic groups are known to have elevated risks of GDM, the RRs in our Asian populations compared with the general population may have been underestimated due to misclassification.

Implications GDM remains a common complication of pregnancy, and ethnicity and increasing BMI are key risk factors for GDM development. We showed that South Asian and Chinese women are at significantly greater risk of developing GDM even at low BMIs. Interventions aimed at reducing excess weight and obesity in South Asians and Chinese women may be less impactful in reducing GDM prevalence.

Supplementary Information The online version of this article (https:// doi.org/10.1007/s00125-020-05356-5) contains peer-reviewed but unedited supplementary material..

Acknowledgements The proposed datasets were linked using unique encoded identifiers and analysed at ICES. Parts of the material are based on data and/or information compiled and provided by the Canadian Institute of Health Information (CIHI). However, the statements expressed in the material are those of the author(s), and not necessarily those of CIHI. This study is based in part on data provided by BORN, part of the Children's Hospital of Eastern Ontario. The interpretation and conclusions contained herein do not necessarily represent those of BORN Ontario. Parts or whole of this material are based on data and/or information compiled and provided by Immigration, Refugees and Citizenship Canada (IRCC) current to June 2019. However, the analyses, conclusions, opinions and statements expressed in the material are those of the author(s), and not necessarily those of IRCC.

Data availability The data that support the findings of this study are available from ICES but restrictions apply to the availability of these data, which were used under license for the current study and so are not publicly available. Data are, however, available from the authors upon reasonable request and with the permission of ICES. 
Funding This project is supported by a PSI Foundation Grant (19-23). SHR is supported by a Diabetes Action Canada Fellowship. This project is supported by ICES, which is funded by an annual grant from the Ontario Ministry of Health and Long-Term Care (MOHLTC). The opinions, results and conclusions reported in this paper are those of the authors and are independent from the funding sources. No endorsement by ICES or the Ontario MOHLTC is intended or should be inferred.

Authors' relationships and activities The authors declare that there are no relationships or activities that might bias, or be perceived to bias, their work.

Contribution statement The study was conceived by SHR and LLL. SHR, LLL and LCR developed the statistical analysis plan. SHR carried out all data preparation and statistical analyses and wrote the first draft of the paper. All authors contributed to the interpretation of the findings and the manuscript's critical revision. All authors approved the final version of the manuscript. SHR is the guarantor of this work and, as such, had full access to all the data in the study and takes responsibility for the integrity of the data and the accuracy of the data analysis.

\section{References}

1. Eades CE, Cameron DM, Evans JMM (2017) Prevalence of gestational diabetes mellitus in Europe: a meta-analysis. Diabetes Res Clin Pract 129:173-181. https://doi.org/10.1016/j.diabres.2017.03. 030

2. Fadl HE, Östlund IKM, Magnuson AFK, Hanson USB (2010) Maternal and neonatal outcomes and time trends of gestational diabetes mellitus in Sweden from 1991 to 2003. Diabet Med 27(4):436-441. https://doi.org/10.1111/j.1464-5491.2010.02978.x

3. Vounzoulaki E, Khunti K, Abner SC, Tan BK, Davies MJ, Gillies CL (2020) Progression to type 2 diabetes in women with a known history of gestational diabetes: systematic review and meta-analysis. BMJ 369:m1361. https://doi.org/10.1136/bmj.m1361

4. Hedderson MM, Williams MA, Holt VL, Weiss NS, Ferrara A (2008) Body mass index and weight gain prior to pregnancy and risk of gestational diabetes mellitus. Am J Obstet Gynecol 198(4): 409.e401-407. https://doi.org/10.1016/j.ajog.2007.09.028

5. Chu SY, Callaghan WM, Kim SY et al (2007) Maternal obesity and risk of gestational diabetes mellitus. Diabetes Care 30(8):2070 2076. https://doi.org/10.2337/dc06-2559a

6. Urquia M, Glazier RH, Berger H, Ying I, De Souza L, Ray JG (2011) Gestational diabetes among immigrant women. Epidemiology 22(6):879-880. https://doi.org/10.1097/EDE. 0b013e31823199ee

7. Hedderson MM, Darbinian JA, Ferrara A (2010) Disparities in the risk of gestational diabetes by race-ethnicity and country of birth. Paediatr Perinat Epidemiol 24(5):441-448. https://doi.org/10.1111/ j.1365-3016.2010.01140.x

8. Kragelund Nielsen K, Andersen GS, Damm P, Andersen A-MN (2020) Gestational diabetes risk in migrants. A nationwide, registerbased study of all births in Denmark 2004 to 2015. J Clin Endocrinol Metab 105(3):e692-e703. https://doi.org/10.1210/ clinem/dgaa024

9. Gagnon AJ, McDermott S, Rigol-Chachamovich J et al (2011) International migration and gestational diabetes mellitus: a systematic review of the literature and meta-analysis. Paediatr Perinat Epidemiol 25(6):575-592. https://doi.org/10.1111/j.1365-3016. 2011.01230.x
10. Shai I, Jiang R, Manson JE et al (2006) Ethnicity, obesity, and risk of type 2 diabetes in women: a 20-year follow-up study. Diabetes Care 29(7):1585-1590. https://doi.org/10.2337/dc06-0057

11. Deurenberg P, Yap M, van Staveren WA (1998) Body mass index and percent body fat: a meta analysis among different ethnic groups. Int J Obes Relat Metab Disord 22(12):1164-1171. https:// doi.org/10.1038/sj.ijo.0800741

12. Wang J, Thornton JC, Russell M, Burastero S, Heymsfield S, Pierson RN Jr (1994) Asians have lower body mass index (BMI) but higher percent body fat than do whites: comparisons of anthropometric measurements. Am J Clin Nutr 60(1):23-28. https://doi. org/10.1093/ajen/60.1.23

13. WHO Expert Consultation (2004) Appropriate body-mass index for Asian populations and its implications for policy and intervention strategies. Lancet 363(9403):157-163. https://doi.org/10.1016/ s0140-6736(03)15268-3

14. Chiu M, Lebenbaum M, Lam K et al (2016) Describing the linkages of the immigration, refugees and citizenship Canada permanent resident data and vital statistics death registry to Ontario's administrative health database. BMC Med Inform Decis Mak 16(1):135. https://doi.org/10.1186/s12911-016-0375-3

15. Lipscombe LL, Hwee J, Webster L, Shah BR, Booth GL, Tu K (2018) Identifying diabetes cases from administrative data: a population-based validation study. BMC Health Serv Res 18(1): 316. https://doi.org/10.1186/s12913-018-3148-0

16. Thompson D, Berger H, Feig D et al (2013) Diabetes and pregnancy. Can J Diabetes 37:S168-S183. https://doi.org/10.1016/j.jcjd. 2013.01.044

17. Thompson D, Capes S, Feig D, Kader T, Keely E, Kozak S (2008) Canadian Diabetes Association 2008 clinical practice guidelines for the prevention and management of diabetes in Canada. Can J Diabetes 32:S168-S180

18. Shah BR, Chiu M, Amin S, Ramani M, Sadry S, Tu JV (2010) Surname lists to identify South Asian and Chinese ethnicity from secondary data in Ontario, Canada: a validation study. BMC Med Res Methodol 10(1):42. https://doi.org/10.1186/1471-2288-10-42

19. Dunn S, Lanes A, Sprague AE et al (2019) Data accuracy in the Ontario birth Registry: a chart re-abstraction study. BMC Health Serv Res 19(1):1001. https://doi.org/10.1186/s12913-019-4825-3

20. Kralj B (2009) Measuring rurality - RIO2008_BASIC: methodology and results. Ontario Medical Association, Toronto. Available from https://content.oma.org//wp-content/uploads/2008riofulltechnicalpaper.pdf

21. Rubin DB (1996) Multiple imputation after 18+ years. J Am Stat Assoc 91(434):473-489. https://doi.org/10.1080/01621459.1996. 10476908

22. Zou G (2004) A modified Poisson regression approach to prospective studies with binary data. Am J Epidemiol 159(7):702-706. https://doi.org/10.1093/aje/kwh090

23. R Core Team (2014) R: a language and environment for statistical computing. R Foundation for Statistical Computing, Vienna

24. Wickham H (2016) ggplot2. Elegant graphics for data analysis. Springer-Verlag, New York

25. Nishikawa E, Oakley L, Seed PT, Doyle P, Oteng-Ntim E (2017) Maternal BMI and diabetes in pregnancy: investigating variations between ethnic groups using routine maternity data from London, UK. PLoS One 12(6):e0179332. https://doi.org/10.1371/journal. pone. 0179332

26. Hedderson M, Ehrlich S, Sridhar S, Darbinian J, Moore S, Ferrara A (2012) Racial/ethnic disparities in the prevalence of gestational diabetes mellitus by BMI. Diabetes Care 35(7):1492-1498. https:// doi.org/10.2337/dc11-2267

27. $\mathrm{Pu}$ J, Zhao B, Wang EJ et al (2015) Racial/ethnic differences in gestational diabetes prevalence and contribution of common risk factors. Paediatr Perinat Epidemiol 29(5):436-443. https://doi.org/ 10.1111/ppe.12209 
28. McDonald R, Karahalios A, Le T, Said J (2015) A retrospective analysis of the relationship between ethnicity, body mass index, and the diagnosis of gestational diabetes in women attending an Australian antenatal clinic. Int J Endocrinol 2015:297420. https:// doi.org/10.1155/2015/297420

29. Hales CN, Barker DJ (2001) The thrifty phenotype hypothesis. Br Med Bull 60:5-20. https://doi.org/10.1093/bmb/60.1.5

30. Su R, Zhu W, Wei Y et al (2016) Relationship of maternal birth weight on maternal and neonatal outcomes: a multicenter study in Beijing. J Perinatol 36(12):1061-1066. https://doi.org/10.1038/jp. 2016.143

31. Innes KE, Byers TE, Marshall JA, Baron A, Orleans M, Hamman RF (2002) Association of a woman's own birth weight with subsequent risk for gestational diabetes. JAMA 287(19):2534-2541. https://doi.org/10.1001/jama.287.19.2534

32. Fernandez-Twinn DS, Ozanne SE (2006) Mechanisms by which poor early growth programs type-2 diabetes, obesity and the metabolic syndrome. Physiol Behav 88(3):234-243. https://doi.org/10. 1016/j.physbeh.2006.05.039

33. Retnakaran R, Hanley AJ, Connelly PW, Sermer M, Zinman B (2006) Ethnicity modifies the effect of obesity on insulin resistance in pregnancy: a comparison of Asian, South Asian, and Caucasian women. J Clin Endocrinol Metab 91(1):93-97. https://doi.org/10. $1210 /$ jc. $2005-1253$

34. Janevic T, Zeitlin J, Egorova N, Balbierz A, Howell EA (2018) The role of obesity in the risk of gestational diabetes among immigrant and U.S.-born women in New York City. Ann Epidemiol 28(4): 242-248. https://doi.org/10.1016/j.annepidem.2018.02.006

35. Kim SY, Sappenfield W, Sharma AJ et al (2013) Racial/ethnic differences in the prevalence of gestational diabetes mellitus and maternal overweight and obesity, by Nativity, Florida, 2004-2007. Obesity 21(1):E33-E40. https://doi.org/10.1002/oby.20025

36. Savitz DA, Janevic TM, Engel SM, Kaufman JS, Herring AH (2008) Ethnicity and gestational diabetes in New York City, 1995-2003. BJOG 115(8):969-978. https://doi.org/10.1111/j. 1471-0528.2008.01763.x

37. Griffith RJ, Alsweiler J, Moore AE et al (2020) Interventions to prevent women from developing gestational diabetes mellitus: an overview of Cochrane Reviews. Cochrane Database Syst Rev 6(6): CD012394. https://doi.org/10.1002/14651858.CD012394.pub3

38. Chan RS-M, Tam W-H, Ho IC-H et al (2018) Randomized trial examining effectiveness of lifestyle intervention in reducing gestational diabetes in high risk Chinese pregnant women in Hong Kong. Sci Rep 8(1):13849. https://doi.org/10.1038/s41598-018-32285-6

39. Chui T, Tran K, Maheux H. Canada's ethnocultural mosaic, 2006 Census. Statistics Canada Catalogue no. 97-562-X. 2008

Publisher's note Springer Nature remains neutral with regard to jurisdictional claims in published maps and institutional affiliations. 